\title{
Simulation Tools to Build Urban-Scale Energy Models: A Review
}

\author{
Alaia Sola *, Cristina Corchero, Jaume Salom ${ }^{\mathbb{D}}$ and Manel Sanmarti \\ IREC Catalonia Institute for Energy Research, 08930 Sant Adrià de Besòs, Spain; ccorchero@irec.cat (C.C.); \\ jsalom@irec.cat (J.S.); msanmarti@irec.cat (M.S.) \\ * Correspondence: asola@irec.cat; Tel.: +34-933-562-615
}

Received: 31 October 2018; Accepted: 16 November 2018; Published: 23 November 2018

\begin{abstract}
The development of Urban-Scale Energy Modelling (USEM) at the district or city level is currently the goal of many research groups due to the increased interest in evaluating the impact of energy efficiency measures in city environments. Because USEM comprises a great variety of analysis areas, the simulation programs that are able to model urban-scale energy systems actually consist of an assemblage of different particular sub-models. In order to simulate each of the sub-models in USEM, one can choose to use either existing specific simulation engines or tailor-made models. Engines or tools for simulation of urban-scale energy systems have already been overviewed in previous existing literature, however the distinction and classification of tools according to their functionalities within each analysis area in USEM has not been clearly presented. Therefore, the present work aims at reviewing the existing tools while classifying them according to their capabilities. The ultimate goal of this classification is to expose the available resources for implementing new co-simulation approaches in USEM, which may reduce the modelling effort and increase reliability as a result of using established and validated simulation engines.
\end{abstract}

Keywords: urban modelling; co-simulation; simulation engines; building stock energy demand

\section{Introduction}

Cities have proved to be one of the largest energy consumer groups and emitters of greenhouse gases in the world [1]. Consequently, urban areas offer a large potential for energy efficiency improvement and greenhouse gases mitigation. One of the key aspects to evolve towards a more sustainable city energy system is to develop integrated or multi-energy systems, where electricity, heating, cooling, and transport interact with each other at various levels. This new urban energy paradigm presents challenges and uncertainty of systems interaction. In order to assess the behavior of urban energy systems, the research field of multi-domain Urban-Scale Energy Modelling (USEM) has experienced a considerable progress in the recent years. USEM platforms are being developed and used as means of anticipating the resulting performance of different scenarios and/or finding the optimal scenario according to given criteria. In fact, USEM comprises a great variety of analysis areas, thus USEM platforms (i.e., simulation programs able to model urban-scale energy systems) actually represent an assemblage of different particular sub-models, as depicted in Figure 1. A sub-model in this context is defined as a model developed specifically to reproduce the behavior of a sub-system within the urban context, aiming at estimating the performance of a simpler system compared to the more complex overall urban-scale energy system.

Based on the previous statements, modelling tools are defined as either specific simulation engines or tailor-made models capable of simulating one part of the urban energy system (one or multiple sub-models). In contrast, heterogeneous USEM platforms are capable of simulating a broad urban energy system including different sub-models. It has been noticed by the authors that the distinction 
between the existing modelling tools and the existing heterogeneous USEM platforms has been partly omitted in existing reviews. However, it is believed that these two concepts must be differentiated. Towards this end, the present review article aims at strictly focusing on the state-of-the-art of the relevant available simulation engines for each sub-model in USEM.

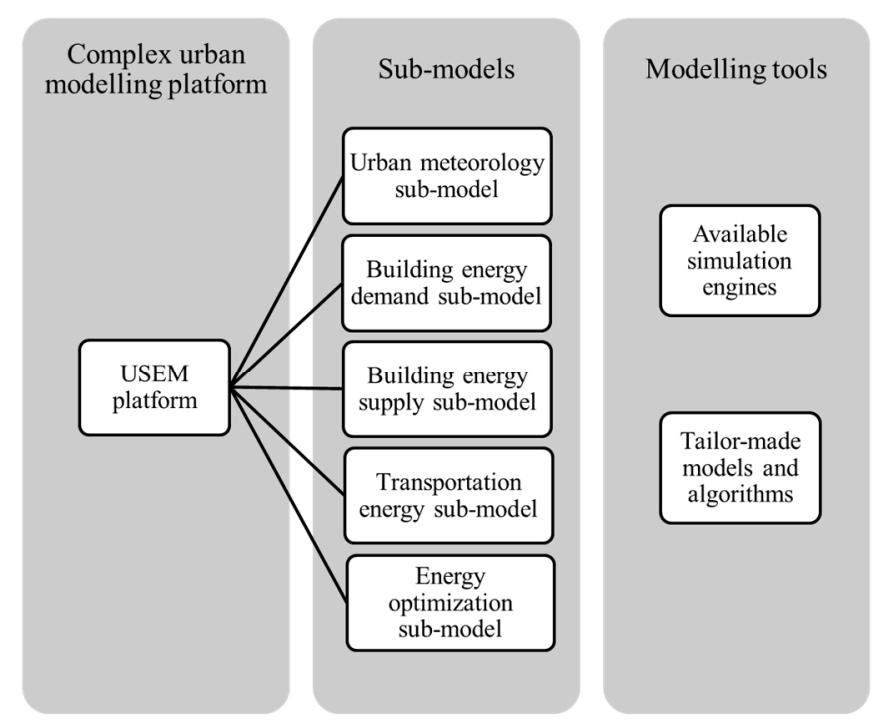

Figure 1. Sub-models in Urban-Scale Energy Modelling platforms.

Engines or tools for the simulation of urban-scale energy systems have already been overviewed in previous existing literature [2,3]. However, the classification of the tools by their functionalities for the simulation of each sub-model (i.e., each basic analysis area) that a complete USEM platform should include has not been clearly presented. Therefore, the present work aims at reviewing the existing tools while classifying them according to their capabilities related to each sub-model in USEM. The ultimate goal of this classification is to expose the available resources for implementing new co-simulation approaches in USEM, which may reduce the modelling effort and increase reliability due to the use of established simulation engines able to build multi-domain USEM platforms. Several modelling tools have been published to date offering the capabilities to simulate one or more of the multiple sub-models that an USEM platform may incorporate. As an example, EnergyPlus simulation engine [4] is used as the tool for the building stock energy demand model in broader USEM platforms such as HUES [5] and Urban Modelling Interface (umi) [6]. In fact, it has been found that existing reviews on urban energy modelling tend to focus on the tools for the simulation of the building stock energy demand, e.g., in $[7,8]$. On the contrary, the present paper intends to provide researchers with an overview of the existing tools for all the analysis areas.

The paper is presented as follows. We begin by offering a description of our review methodology (Section 2). Tools for the simulation of each of the five sub-models of an USEM platform are then reviewed in turn. Tools for urban meteorology analysis are introduced in Section 3. The review of tools for building energy systems modelling is divided in Sections 4 and 5, i.e., tools for building energy demand and supply analysis, respectively. Transportation energy modelling is reviewed in Section 6 . Tools for energy optimization modelling are discussed in Section 7. Conclusions are presented in Section 8. Finally, the selection of tools and simulation engines in this study is also classified in different Tables which indicate the main capabilities of each tool concerning topics such as the analyses of the environment, energy demand, energy generation, energy distribution, and optimization in an urban-scale energy system. 


\section{Review Methodology}

The subject area of Urban-Scale Energy Modelling encompasses numerous techniques and application domains. We therefore conducted a dedicated survey of the literature in order to identify the diversity of the existing engines or tools that have been used for the simulation of urban-scale energy systems. The work is based on the academic experiences of the authors besides the literature survey. The analysis performed with literature review includes findings from the sources SCOPUS and Google Scholar. Since the work has been structured in various sections dedicated to each of the sub-models in USEM, different combinations of terms were used in the search engines depending on the target of the article crawl.

Article crawls were performed within the period of 1997 (first articles on image-processing software for urban-scale environmental model) to early 2018. The identified papers primarily represent the past decade and confirm that the review is an assessment of current practice. Also, in order to identify a manageable subset of papers, the results were filtered by excluding subject areas irrelevant to the aim of our work, such as biological and health sciences. The remaining studies were reviewed and classified. These studies generally belong to the fields of urban climate studies, building simulation, district networks simulation, micro- and macrosimulation of transportation, and optimization engines, all with relevance to energy systems.

\section{Tools for Urban Meteorology Analysis}

Energy systems in cities interact with the atmosphere over a wide range of scales. This fact together with the increasing share of humans living in cities has promoted the research on urban meteorology (the study of the effect of urban areas on local weather variables) during the last decades. It is therefore known that in order to develop an accurate USEM platform, the context data-meteorological and environmental-is of great importance. Accordingly, some of the available tools aimed at modelling the main physical processes that characterize the urban meteorology are discussed in this section.

\subsection{Meteorological Data}

Meteorological data is commonly used in hourly values for building simulation. There are many meteorological data sources available on the web, both from national meteorological services and commercial data bases (such as Meteonorm [9]). The first kind of data source is based on measured data, whereas the second one is rather synthetic data that are constructed from monthly values with models.

Although it is well known that there is a great sensitivity of building heating and cooling demands to climate change, the standard weather files rarely consider this phenomenon. In order to cope with this limitation, additional tools are required, i.e., climate change weather file generator tools. Two available tools with wide industry recognition are CCWorldWeatherGen [10] and WeatherShift ${ }^{\mathrm{TM}}$ [11]. CCWorldWeatherGen is a freely available tool that integrates future climate scenarios into the widely used weather file formats within simulation TMY2 and EPW. In a similar way, the commercial WeatherShift ${ }^{\mathrm{TM}}$ toolkit produces EPW weather files adjusted for changing climate conditions. These tools are based on different general circulation models and different Assessment reports by the Intergovernmental Panel on Climate Change (IPCC) on the emission scenarios that provide projections of possible future climate change.

\subsection{Urban Climate Modelling}

Besides climate change, the urbanized areas themselves are another factor that should be included in an urban meteorology sub-model. The morphology of buildings and their heat emissions influence local temperatures and air circulation and alter the formation of precipitation and the frequency and intensity of thunderstorms [12]. More in detail, with the presence of a very dense building stock, more shortwave radiation is absorbed, less longwave radiation is emitted, and the mean wind speed is lower, so that the mean air temperature is higher. This is the so-called Urban Heat Island (UHI) effect, 
which is fostered by anthropogenic heat sources and the relative lack of vegetated surfaces in urban areas. UHI is the main factor influencing the variations in building stock energy demand between urban and rural areas [13]. Due to this fact, the meteorological data usually available in commercial databases may not be representative enough to model the energy use in urban areas. At this point, the urban climate modelling (i.e., the modelling of the ways in which cities influence atmospheric thermodynamics) becomes essential to reveal the trend of the urban heat load.

Urban climate assessment tools can be classified under mesoscale and microclimate models. On one hand, a modelling tool classified within the mesoscale modelling approach is well suited to predicting phenomena in the city block scale, i.e., $100 \mathrm{~km}$ order with the smallest applicable mesh size being about $1 \mathrm{~km}$. On the other hand, the microclimate modelling approach is useful to predict detailed spatial distributions of flow, temperatures, and scalar fields inside complex urban areas at building or district scale [14]. Mesoscale and microclimate models may be used separately or simultaneously, depending on the targeted resolution level. However, in general terms, in order to evaluate the energy use in city districts, microclimate models are of great use. Urban microclimate modelling ranges from radiation analyses that take focus on the short and longwave radiant exchange within the urban geometries (e.g., in reference [15]) to more detailed multi-scale atmospheric flow modelling by means of three-dimensional computational fluid dynamics (CFD) (e.g., in reference [16]).

The urban microclimate assessment tool ENVI-met [17] is a CFD-based tool that takes into account shortwave and longwave radiation, transpiration, evaporation and sensible heat flux from vegetation and water, as well as heat exchange with the soil. The ENVI-met 4.0 works with prescribed dynamic boundary conditions (temperature, wind velocity, humidity) and in such way generates 'corrected' urban climatologic parameters. Furthermore, it includes 3D modelling and allows the user to specify each element's physical properties on the building's façades [18]. In addition to ENVI-met, several urban microclimate models exist that are freely available and could be applied to urban meteorology and climatology. The RayMan model [19] is a tool for the simulation of radiation flux densities and mean radiant temperature from the three-dimensional surroundings in simple and complex environments. RayMan allows calculating sunshine duration with or without sky view factors; estimating daily mean, max or summing of global radiation; and calculating shadows for existing or future complex environments. SkyHelios [20] is a tool to calculate global radiation, sunshine duration, shade, roughness, wind speed, and sky view factors in high spatial and temporal resolution by using a graphic processor. Additionally, it provides an interface to RayMan and other models, as well as import possibility of GIS files and formats. MUKLIMO_3 [21] is a non-hydrostatic climate model which can be considered a mesoscale model in contrast to ENVI-met, SkyHelios and RayMan tools (which are considered as microscale models). As an urban climate model, MUKLIMO_3 was developed to simulate the near-surface meteorology of urban areas [22]. It simulates the atmospheric temperature, humidity and wind field on a 3D grid. Being a mesoscale model, the spatial resolution of the model can vary from a few meters with resolved buildings to several hundred meters with parametrized building environments. One simulation tool extensively applied for solar and daylighting studies is the non-commercial software Radiance [23]. This tool includes a model that uses vector data to calculate solar energy incident on buildings, accurately calculates luminance and radiance, and models both electric light and daylight, all based on urban obstructions in a volumetric 3D model. Radiance is used, for example, in the urban modelling platforms URBANopt [24] and umi [6]. The modelling tool Urban Weather Generator (UWG) $[25,26]$ calculates air temperatures inside urban canyons from measurements at an operational weather station located in an open area outside a city. The tool can be used alone (as a data pre-processing step) or coupled to existing programs (thus using the co-simulation approach). Therefore, UWG calculates the hourly values of urban air temperature and humidity by modelling UHI, based on neighborhood-scale energy balances. An application of the UWG is presented in [27], where UWG is combined with a parametric simulation module that works either stand-alone or together with the urban platform umi in Rhinoceros 3D software [28]. 
In general, and at the present stage of USEM development, the use of a variety of sub-models for urban climate modelling is well-established in either an integrated manner (including at source-code level the mathematical modelling of urban climate) or in a sequential manner (using a simulation engine or model to pre-process the meteorological data that will be subsequently input to other sub-models of the USEM platform). In fact, the main observed approach in USEM is the sequential use of existing urban climate modelling tools. For example, this capability is implemented in CitySim platform [13] with the use of three climate models developed by [29] (i.e., a macro, meso and an urban canopy model) to predict temperature, wind and pressure field in the city considering the building stock. The urban climate models are run as a pre-process to modify the climatic inputs to the other sub-models in CitySim.

\section{Tools for Building Energy Demand Modelling}

Over the last decades, detailed individual building energy modelling has become an established mode of analysis for building designers. Consequently, there are a large number of modelling tools (simulation engines or software) available to simulate the energy demand of a building. At an urban level, the analysis of the energy demand of buildings includes both a characterization of the building stock itself and the simulation of the energy demand of the buildings integrating this stock.

\subsection{Building Stock Characterization}

Building stock characterization consists of two steps: First, the building typology (or also called building archetype) identification and, second, its topological (geometry) definition and eventually representation. This characterization is one of the critical points, especially in case of analyzing existing urban areas, since the information must be extracted from existing data sets. The problem complexity is significantly reduced in case of neighborhoods in planning phase due to the more complete information on both typologies and thermal characteristics of the buildings, where characterization may be generated from scratch.

Firstly, the building typology (also called 'archetype') identification comprises the definition of a set of parameters (use, age and shape) for each building. Given the diversity of building constructions, systems and occupancy patterns in a city, the typology characterization is normally done by grouping a set of buildings and defining them with the average properties of a real building sample with the same characteristics. Secondly, the building topological (geometry) definition acquires the information from cadastral data bases, statistical estimates, sampling and remote sensing by image processing technologies. Digital image processing is the process of assigning a pixel (or groups of pixels) of remote sensing image to a land cover or land use class. In fact, digital image processing has been recognized for a wide scope of applications (not limited to urban energy modelling), which has led to an important progress on this field (see e.g., references [30-32]). An application example is the LT Urban method developed by references [33,34], which uses digital image processing in order to obtain the urban geometries of non-residential buildings for the simplified energy demand model. LT Urban uses Digital Elevation Models derived from ortophotos. In a similar way, this approach was used by references $[35,36]$ to obtain environmental parameters, such as shadowing distribution, daylight availability, sky view factors and so on. In this case, the authors used the Image Processing Toolbox within Matlab [37]. Other approaches include the laser scanning for building characterization applied by reference [38] and the satellite images and aerial photos used by reference [39]. It is interesting to note that reference [39] deduced the building construction period by comparing satellite images taken in different years. Both methodologies have been applied to study possible improvements or feasibility of district heating systems in what may be considered as low-density settlements. These kinds of tools have been shown to be of great utility, especially in areas with low quality cadastral information.

Data for building geometry definition may be combined from two disparate data streams. In order to complement the use of digital image processing, the integration of this approach and Geographical Information Systems (GIS) technologies has been applied widely for building geometry 
characterization. GIS are computer programs for the acquisition, storage, analysis and display of geographic data, which allow withdrawing information regarding the geometry and typology of the existing buildings. The most frequently used tools for such purposes are ArcGIS, e.g., used in references [40,41], and the open source free Quantum GIS or QGIS, e.g., used in references [42,43]. Some of these tools can be coupled to 3D modelling tools in order to project a $2 \mathrm{D}$ geometry onto a complex 3D surface, e.g., ArcGIS can be coupled to Sketchup [44], as done in reference [45]. The use of 3D GIS software like SketchUp or ESRI CityEngine [46] is common and mostly used for data creation focused on building geometry (without semantic information). In practice, most of the GIS models are relatively poorly attributed when referring to semantical information acquisition. In order to address this constraint, a framework for integrating the Building Information Modelling (BIM) technology into GIS is proposed in the literature [47]. BIM is a process involving the generation and management of digital representations of both physical and functional characteristics of a building, but it is mostly used in small scale projects. The integration of BIM into GIS leads to the concept of City Information Modelling (CIM). An example of a well-developed and established semantic model in digital city is CityGML (City Geography Markup Language) [48]. CityGML is an open standardized data model and exchange format to store digital 3D models of cities and landscapes, which is quickly being adopted (mainly in Europe) as an international exchange format standard [49]. This kind of approach has been used in several platforms for city-scale building load simulation in order to gain accuracy in volumetric/geometric definition of existing building stock. Examples of the use of CityGML for building stock characterization are the 3D city model of the city of Ludwigsburg by reference [50], the 3D modelling of the city of Essen by reference [51], the tool TEASER by reference [52], or the web-based data and computing platform CityBES by reference [53]. Finally, the geometric modelling of the building stock can be done as a computer-aided design (CAD) representation ('manual' drawing) of each building or typology, for example with common CAD tools such as AutoCAD [54]. Many of these tools offer the feature of using Google Earth [55] to import GIS information in order to subsequently analyze, place, and orient the design of the buildings.

\subsection{Building Energy Demand Modelling}

The sub-model for building stock energy demand calculation within USEM has broadly used well-known commercial or public-domain software. In fact, it is common to find urban platforms that put an emphasis on the demand side of the urban energy system and ignore the energy supply side. In this case, models can be classified as Urban Building Energy Modelling (UBEM) platforms, which mostly simulate the demand endogenously, that is, by including equations that provide the demand under different conditions as an output of the model).

The tools for building energy demand simulation analyzed in this study follow a bottom-up approach. Such approach extrapolates the estimated energy consumption of a representative set of individual building archetypes to a wider urban area [56], thus merging detailed individual building energy models and large-scale building stock models. The opposite approach for energy demand modelling is the so-called top-down approach, which treats the residential sector as energy sink and is not concerned with individual end-uses. The latter utilizes historic aggregate energy values and from them computes the energy consumption of the housing stock as a function of top-level variables (e.g., gross domestic product, unemployment, inflation), energy price, and general climate [56]. In general, models for energy conversion inside a building (e.g., models for HVAC equipment, boilers and storage devices) are relatively simple and typically based on heat and mass balance equations and equipment performance parameters or curves. Notwithstanding this, it must be noted that detailed building energy demand modelling is a key element for the subsequent evaluation of different energy supply systems at a district or city level.

Bottom-up modelling methodologies applied in UBEM can be classified in two main categories: Statistical and engineering modelling methods. An overview of these two different energy demand modelling methodologies is done in reference [56]. On the one hand, engineering models estimate 
the dynamic energy demand by taking into account building physics, climate, occupancy, usage of equipment, etc. and can provide profiles of individual (typical) buildings with high temporal resolution. For example, this kind of model is used in the USEM platform HUES [5]. On the other hand, statistical methods result from regression analyses which establish the relationship between building energy consumption and its defined end-uses and climatic conditions.

There are many representative review papers which compare the features of the major existing building-level energy simulation tools used for UBEM [6,57,58]. For the aim of the present work, a selection of the most representative building energy demand simulation tools based on the engineering modelling approach and employed in both UBEM and USEM platforms has been done. The categorization and technical attributes of the selected tools are summarized in Table 1.

- DOE-2 [59], used for example to simulate the heating and cooling loads and energy usage for 144 residential and 120 commercial prototypes/climate combinations in reference [60]. It models building heating, cooling and electricity demand.

- eQUEST [61] (derived from DOE-2), used for example in reference [62] in conjunction with DOE-2 to obtain day-specific estimates of electricity and natural gas consumption within the residential and commercial sectors in a city. eQUEST has an extensive library of default values for building characteristics for several building types in the United States.

- ESP-r [63], used for example by reference [64] for the calculation of space heating and cooling of 17,000 houses in the Canadian hybrid residential end-use energy and emissions model (CHREM). It models building heating, cooling, appliances, lighting and domestic hot water demand.

- EnergyPlus [4] (partly based on DOE-2 software), used for instance by reference [43] for thermal building simulations at large urban scale, as well as in the USEM platforms previously mentioned HUES and umi. It models building heating, cooling, appliances, lighting and domestic hot water demand.

- HASP / ACLD [65], widely used by Japanese authors, e.g., used in reference [66] to simulate the energy use in buildings in a representative district. It models the indoor temperature, humidity and building thermal loads. A comparison of HASP / ACLD features and capabilities with the EnergyPlus software in terms of air-conditioning evaluation of buildings is done by reference [67].

- HOT2000 [68], mainly used by Canadian authors, e.g., used in reference [69] to perform batch simulations for 8767 house files based on the Canadian stock. Similar to HASP / ACLD, it models building heating and cooling demand.

- $\quad$ TRNSYS [70], used by references [71,72] for example to couple it with urban microclimate engines to include the effects of urban microclimate in building energy performance simulations of the building stock. TRNSYS is designed to simulate the transient performance of thermal energy systems while building input data is entered through a dedicated visual interface (TRNBuild).

- Modelica [73] is an object-oriented simulation language that offers an extensive set of standard libraries, with models for control, thermal, electrical and mechanical systems. These are used to develop the base for modelling highly-specialized applications. Examples of relevant Modelica libraries within urban energy modelling are the Building library by reference [74] and the AixLib library by reference [75]. Several multi-domain modelling and simulation solutions existing in USEM are based on Modelica, e.g., the work presented in reference [76]. Some of simulation tools able to execute Modelica are Dymola, MathModelica, MapleSim, and Open-Modelica.

- PolySun [77] models building heating, cooling and domestic hot water demand. Thermal and electrical models are presented all in one tool. An example of the use of PolySun for urban energy modelling is presented in reference [78].

- IDA ICE or IDA Indoor Climate and Energy [79], used by reference [80] in order to assess the effect of urban modifications on indoor air temperature and the building cooling load. It consists of thermal simulation software that models heating, cooling, ventilation, and lighting systems in a building. 
These simulation engines may also be used in a sequential manner, thus the output of one of them is subsequently used as the input for the other one. For instance, in the model developed by reference [81], DOE-2 building loads are simplified and used in a sequential manner as input for TRNSYS simulations, which are in turn used to model the energy supply system. TRNSYS and Modelica simulation environments were combined by reference [82] in order to benefit from the advantages of employing the specialized modelling capabilities of TRNSYS together with the ability of performing rapid prototyping within Modelica for large-scale energy systems modelling. Similarly, a model that allows EnergyPlus to conduct co-simulation with various simulation tools (e.g., with Modelica) is presented in reference [83]. Another approach for co-simulation of whole-building energy modelling is OpenStudio cross-platform [84]. This platform is a collection of software tools that interface with EnergyPlus input and output files and manage the simulations. In this case, the tool supports the co-simulation with advanced daylight analysis using Radiance software, and it includes graphical interfaces (such as a plug-in to Google SketchUp) to create building geometry [85].

As for the tools based on bottom-up statistical techniques, these are applied to determine the energy demand contribution of end-uses in buildings (normally including behavioral aspects) based on data obtained from energy bills, simple surveys, or others [56]. Common programming languages for this kind of simulation tools are Matlab, R [86], GradeStat [87], Python [88], or Java [89]. Examples of the use of statistical techniques to create forecasting models of energy consumption and load demand peak are described in references [90-92]. 
Table 1. Characteristics of reviewed simulation tools for building energy demand in USEM.

\begin{tabular}{|c|c|c|c|c|c|c|c|c|c|c|c|c|c|c|c|c|}
\hline & $\begin{array}{l}\text { Transient/ } \\
\text { Static }\end{array}$ & $\begin{array}{l}\text { Radiation } \\
\text { Analysis }\end{array}$ & $\begin{array}{l}\text { Coupling } \\
\text { with GIS }\end{array}$ & $\begin{array}{l}\text { Building } \\
\text { Geometry }\end{array}$ & $\begin{array}{l}\text { Energy } \\
\text { Demand } \\
\text { Modelling } \\
\text { Approach }\end{array}$ & $\begin{array}{l}\text { Energy } \\
\text { Demand } \\
\text { Modelling }\end{array}$ & $\begin{array}{c}\text { Types of } \\
\text { Building } \\
\text { Energy } \\
\text { Demand }\end{array}$ & $\begin{array}{c}\text { Impact of } \\
\text { User } \\
\text { Behavior on } \\
\text { Energy } \\
\text { Demand }\end{array}$ & $\begin{array}{l}\text { Modelling of } \\
\text { Energy } \\
\text { Generation }\end{array}$ & $\begin{array}{l}\text { District } \\
\text { Thermal } \\
\text { Network }\end{array}$ & $\begin{array}{l}\text { Electricity } \\
\text { Network }\end{array}$ & $\begin{array}{c}\text { Gas } \\
\text { Network }\end{array}$ & $\begin{array}{c}\text { Building } \\
\text { Design } \\
\text { Optimization }\end{array}$ & Time Scale & Availability & References \\
\hline DOE-2 & $\mathrm{T}$ & $\mathrm{x}$ & - & $\mathrm{x}$ & Eng & Endo & $\mathrm{H}, \mathrm{C}, \mathrm{V}, \mathrm{L}$ & - & $\begin{array}{l}\text { PV, GSHP, } \\
\text { TES, boiler, } \\
\text { chiller }\end{array}$ & - & - & - & $x^{1}$ & hourly & free & [59] \\
\hline eQUEST & $\mathrm{T}$ & $\mathrm{x}$ & $\mathrm{x}$ & $\mathrm{x}$ & Eng & Endo & $\mathrm{H}, \mathrm{C}, \mathrm{V}, \mathrm{L}$ & - & $\begin{array}{l}\text { PV, GSHP, } \\
\text { TES, boilers, } \\
\text { chillers }\end{array}$ & - & - & - & $x^{1}$ & hourly & free & [61] \\
\hline ESP-r & $\mathrm{T}$ & $\mathrm{x}$ & - & $\mathrm{x}$ & Eng & Endo & $\begin{array}{c}\text { H, C, A, L, } \\
\text { DHW }\end{array}$ & $\mathrm{x}$ & $\begin{array}{c}\mathrm{PV}, \text { solar } \\
\text { thermal, } \\
\text { boilers, } \\
\text { chillers }\end{array}$ & - & - & - & $x^{1}$ & sub-hourly & $\begin{array}{c}\text { free, } \\
\text { open-source }\end{array}$ & [63] \\
\hline EnergyPlus & $\mathrm{T}$ & $\mathrm{x}$ & $\mathrm{x}$ & $\mathrm{x}$ & Eng & Endo & $\begin{array}{l}\text { H, C, A, L, } \\
\text { DHW }\end{array}$ & $x$ & $\begin{array}{l}\text { PV, BIPV, } \\
\text { cogeneration, } \\
\text { boilers, } \\
\text { chillers }\end{array}$ & - & - & - & $x^{1}$ & sub-hourly & $\begin{array}{c}\text { free, } \\
\text { open-source }\end{array}$ & [4] \\
\hline HASP/ACLD & $\mathrm{T}$ & - & - & $x$ & Eng & Endo & $\mathrm{H}, \mathrm{C}$ & - & - & - & - & - & - & hourly & free & [65] \\
\hline НОТ2000 & $\mathrm{T}$ & - & - & $\mathrm{x}$ & Eng & Endo & $\mathrm{H}, \mathrm{C}$ & - & - & - & - & - & - & annual & free & [68] \\
\hline TRNSYS & $\mathrm{T}$ & $\mathrm{x}$ & $\mathrm{x}$ & $\mathrm{x}$ & Eng & Endo & $\mathrm{H}, \mathrm{C}, \mathrm{V}$ & $\mathrm{x}$ & $\begin{array}{c}\text { PV, solar } \\
\text { thermal, } \\
\text { GSHP, TES, } \\
\text { boilers, } \\
\text { chillers }\end{array}$ & $\mathrm{x}$ & - & - & $x^{1}$ & sub-hourly & $\begin{array}{l}\text { commercial, } \\
\text { open-source }\end{array}$ & [70] \\
\hline Modelica & $\mathrm{T}$ & $\mathrm{x}$ & - & $\mathrm{x}$ & Eng & Endo & $\mathrm{H}, \mathrm{C}, \mathrm{A}, \mathrm{L}$ & $\mathrm{x}$ & $\begin{array}{c}\text { PV, GSHP, } \\
\text { boilers, } \\
\text { chillers }\end{array}$ & $\mathrm{x}$ & $\mathrm{x}$ & - & $\mathrm{x}$ & sub-hourly & $\begin{array}{c}\text { open-source, } \\
\text { free, } \\
\text { commercial }\end{array}$ & [73] \\
\hline Polysun & $\mathrm{T}$ & $\mathrm{x}$ & - & $\mathrm{x}$ & Eng & Endo & $\begin{array}{l}\text { H, C, E, } \\
\text { DHW }\end{array}$ & $\mathrm{x}$ & $\begin{array}{l}\mathrm{PV} \text {, solar } \\
\text { thermal, wind, } \\
\text { GSHP }\end{array}$ & $\mathrm{x}$ & $\mathrm{x}$ & - & $x^{2}$ & sub-hourly & commercial & [77] \\
\hline IDA ICE & $\mathrm{T}$ & $\mathrm{x}$ & - & $\mathrm{x}$ & Eng & Endo & $\mathrm{H}, \mathrm{C}, \mathrm{V}, \mathrm{L}$ & $\mathrm{x}$ & PV, GSHP & $\mathrm{x}$ & - & - & $x^{1}$ & sub-hourly & $\begin{array}{l}\text { commercial, } \\
\text { open-source }\end{array}$ & [79] \\
\hline
\end{tabular}

$\mathrm{S}=$ Steady-state; $\mathrm{T}$ = Transient; Eng = Engineering model; Sta = Statistical model; Endo = Endogenous; Exo = Exogenous; $\mathrm{H}=\mathrm{Heating} ; \mathrm{C}=\mathrm{Cooling} ; \mathrm{V}=$ Ventilation; $\mathrm{A}=\mathrm{Appliances} ;$

$\mathrm{L}=$ Lighting; $\mathrm{E}=$ Electricity, DHW = Domestic Hot Water; PV = Photovoltaics; GSHP = Ground-source heat pump; CHP = Combined Heat\&Power; BIPV = Building Integrated

Photovoltaics; HP = Heat Pump; TES = Thermal Energy Storage; ${ }^{1}$ Coupled with generic optimization programs; ${ }^{2}$ Coupled with Matlab \& Polysun Inside (a Polysun plug-in). 


\section{Tools for Building Energy Supply Modelling}

In order to fully simulate the energy system of a city or district, the modelling of the supply side is also of high importance. The relationship between the performance of energy supply systems and the energy demand profiles of buildings determines the main energy flows of the district or city. Therefore, one of the main goals of urban energy simulation should be to help forecasting potential problems of supply and demand mismatch and propose scenarios to overcome barriers. In order to achieve this, the energy supply system sub-model should simulate both the energy generation plants (how they dynamically behave related to their efficiency and weather-dependency) and the energy distribution networks (to observe potential network capacity overloads and/or help sizing the networks themselves).

In general, the simulation of district energy systems requires the calculation of the energy flows of networks and grids by considering the energy supply from both central systems and distributed systems (if included in the analysis). On the one hand, typical building electricity supply systems are composed of two sources: Grid electricity from central systems and the so-called Distributed Energy Resource Systems (DERs) (which allow an energy system to be partially or completely independent from the grid). On the other hand, the same concept may be considered for the thermal supply, as heating and cooling can be sourced from both a thermal district network supplied by a central system and/or from distributed thermal energy generation. Different tools to simulate building energy supply systems have been reviewed by references [93-95]. The categorization and technical attributes of the selected tools for the present study are provided in Table 2.

\subsection{Energy Generation Modelling}

Modelling of both central and decentralized energy conversion or generation plants may be done by developing a customized model, or also by using standard libraries of available simulation engines or tools. The use of TRNSYS, DOE-2, and Modelica for this purpose is frequent. Some examples are the use of Modelica for thermal simulation of natural gas cogeneration power plants, absorption chillers and thermal solar collectors described in reference [43], or the use of TRNSYS for analyzing different energy supply scenarios including Combined Heat and Power (CHP) units, ground- and water-source heat pumps, and boilers found in [81].

Focusing on DERs evaluation tools, a variety of reviews on software for design and optimization of DER technology can be found in the literature $[3,95,96]$. Some of the most known tools for DERs simulation are energyPRO [97], HOMER [98], DER-CAM [99], RETScreen [100], or EnergyPLAN [101]. Differently to tools such as TRNSYS, DOE-2, and Modelica, this type of simulation engines is more focused on techno-economic analysis of the consequences of different energy investments in relation to the availability of distributed energy resources, rather than on the specific physical impact of DERs technologies on the distribution grids and networks. This kind of software do not normally model detailed building stock energy demand as the tools described in Section 4 do, but they generally utilize real load profiles or load profiles generated by other tools for their analysis.

\subsection{Energy Distribution Modelling}

The proper modelling of the dependency of energy demand systems on the electrical grid and thermal district networks is desirable, as the energy carrier infrastructures are a significant element in the potential for optimization of district energy systems. Modelling of distribution systems will provide information on the possibility for reduction of transmission losses and problems related to congestion in distribution systems, as well as the possibility of interaction between the building energy consumers/producers and the distribution systems. However, until now many USEM published in the literature ignored this sub-model, as they focus on building energy demand modelling and local energy generation, assuming all the rest of the required energy by the building stock is guaranteed on a district scale. Therefore, one aspect to emphasize for the future development of USEM is the 
consideration of the detailed modelling of the energy infrastructures. Indeed, there are a variety of available simulation engines for energy infrastructure modelling, thus energy distribution modelling within more complex USEM platforms should take advantage of the available tools.

An existing review of a quite large number of software tools for district heating modelling is presented in reference [102]. One such tool is Modelica, used by [43] in their simulation of the thermal energy distribution network in an urban area. Yet, it is not documented how detailed the model is in this case. Generally, the simplified models of the district thermal energy network tend to focus on the calculation of heat losses. However, the simulation of other aspects may also be of interest, as e.g., network storage capability, inertia (time delays in the network), distribution temperature, or operation strategies that involve dynamic temperature control [103]. These other parameters are especially of interest if a more interactive network is foreseen in order to upgrade the system performances or to deal with very low energy demand buildings [104]. In this sense, it is advisable to pay attention to the capabilities of commercial district energy models such as TERMIS [105]. This software can create models of both simple and complex district energy pipeline systems besides including multiple generation plants, heat exchangers, pumps, valves and other equipment that affect pipeline operation. In addition to TERMIS, examples of other commercial tools for district heating and cooling (DHC) calculations are NetSim [106] and PolySun [77]. NetSim can perform accurate district network calculations considering parameters such as pressure, velocity, and temperature. PolySun (although not originally designed for network simulations) can provide detailed hydraulics modelling to simulate energy flows and pumping power requirements for district heating networks with decentralized pumps. Other available software is Apros [107], which can be used to model and analyze district heating networks and also long-distance district heat transmission circuits. TRNSYS has been used in more than one work [108-113] for thermal energy networks simulation, mainly by developing new models in the TRNSYS library to better simulate the hydronic systems for space heating, DHW and district heating systems. Also, the UBEM tool CityBES (despite being focused on the simulation of building stock energy demand) allows the evaluation of the feasibility of advanced DHC systems through the co-simulation between DHC models in Modelica and building models in EnergyPlus [53].

Other than thermal energy networks simulation, there are simulation tools in the market that have electricity and/or gas distribution modelling capabilities. NEPLAN [114] is a tool that performs optimization of electrical, water, gas, and district heating networks. It can perform flow and energy loss calculations for microgrids as well as hydraulic modelling of district heating networks.

Focusing on power grid simulation, there is a large variety of free, open-source and commercial software packages available because of the engineering requirements of the industry and providers. Power system modelling is a broad field and consequently the type of models and assumptions used varies considerably among software packages. Existing simulation tools can differ in time-scale of the simulations (steady-state vs. transient), and in domain (power generation, transmission, platforms and the classification of their capabilities is presented in [115]. Examples of widely used commercial software packages for power system design and operation applications are DigSILENT PowerFactory [116], MODEST [117], the Matlab tool MATPOWER [118], PyPower (a port of MATPOWER to the Python programming language) [119], ETAP [120], IPSA 2 [121]. 
Table 2. Characteristics of reviewed simulation tools for building energy supply in USEM.

\begin{tabular}{|c|c|c|c|c|c|c|c|c|c|c|c|c|}
\hline & $\begin{array}{l}\text { Transient/ } \\
\text { Static }\end{array}$ & $\begin{array}{l}\text { Coupling } \\
\text { with GIS }\end{array}$ & $\begin{array}{l}\text { Endogenous/ } \\
\text { Exogenous } \\
\text { Energy } \\
\text { Demand } \\
\text { Modelling } \\
\end{array}$ & $\begin{array}{c}\text { Types of } \\
\text { Building } \\
\text { Energy } \\
\text { Demand } \\
\text { Considered } \\
\end{array}$ & $\begin{array}{l}\text { Modelling of } \\
\text { Energy } \\
\text { Generation }\end{array}$ & $\begin{array}{l}\text { Thermal } \\
\text { Network }\end{array}$ & $\begin{array}{l}\text { Electricity } \\
\text { Network }\end{array}$ & $\begin{array}{c}\text { Gas } \\
\text { Network }\end{array}$ & $\begin{array}{c}\text { Energy } \\
\text { System } \\
\text { Optimization }\end{array}$ & Time Scale & Availability & References \\
\hline HOMER & $\mathrm{T}$ & - & Exo & $\mathrm{T}, \mathrm{E}$ & $\begin{array}{l}\text { PV, wind, hydro, } \\
\text { biomass, } \\
\text { microturbines, fuel } \\
\text { cells, batteries, } \\
\text { hydrogen storage }\end{array}$ & $\mathrm{x}$ & $\mathrm{x}$ & - & $\mathrm{x}$ & sub-hourly & commercial & [97] \\
\hline TERMIS & $\mathrm{s}$ & - & Exo & $\mathrm{T}$ & Exogenously & $\mathrm{x}$ & - & - & $\mathrm{x}$ & - & commercial & [105] \\
\hline NetSim & $\mathrm{S}$ & $\mathrm{x}$ & Exo & $\mathrm{T}$ & Exogenously & $x$ & - & - & $\mathrm{x}$ & - & commercial & [106] \\
\hline Apros & $\mathrm{T}$ & - & Exo & $\mathrm{T}, \mathrm{E}$ & $\begin{array}{l}\text { Solar thermal, } \\
\text { cogeneration, } \\
\text { thermal power } \\
\text { plants }\end{array}$ & $\mathrm{x}$ & $\mathrm{x}$ & - & $\mathrm{x}$ & hourly & commercial & [107] \\
\hline NEPLAN & $\mathrm{T}$ & $\mathrm{x}$ & Exo & $\mathrm{T}, \mathrm{E}$ & Exogenously & $\mathrm{x}$ & $\mathrm{x}$ & $\mathrm{x}$ & $\mathrm{x}$ & hourly & $\begin{array}{l}\text { commercial, } \\
\text { open-source }\end{array}$ & [114] \\
\hline $\begin{array}{l}\text { DigSILENT } \\
\text { PowerFactory }\end{array}$ & $\mathrm{T}$ & - & Exo & E & Exogenously & $\mathrm{x}$ & - & - & $\mathrm{x}$ & hourly & commercial & [116] \\
\hline MODEST & $\mathrm{T}$ & - & Exo & $\mathrm{T}, \mathrm{E}$ & $\begin{array}{c}\text { Wind, hydro, } \\
\text { biomass, HP, CHP, } \\
\text { boilers }\end{array}$ & $\mathrm{x}$ & - & $\mathrm{x}$ & $\mathrm{x}$ & hourly & commercial & [117] \\
\hline MATPOWER & $\mathrm{s}$ & - & Exo & E & Exogenously & - & $\mathrm{x}$ & - & $\mathrm{x}$ & - & $\begin{array}{c}\text { free, } \\
\text { open-source }\end{array}$ & [118] \\
\hline PYPOWER & $\mathrm{s}$ & - & Exo & E & Exogenously & - & $\mathrm{x}$ & - & $\mathrm{x}$ & - & $\begin{array}{c}\text { free, } \\
\text { open-source }\end{array}$ & [119] \\
\hline ETAP & $\mathrm{T}$ & $\mathrm{x}$ & Exo & E & $\mathrm{PV}$, wind, batteries & - & $\mathrm{x}$ & - & $\mathrm{x}$ & hourly & commercial & [120] \\
\hline IPSA 2 & $\mathrm{~T}$ & $\mathrm{x}$ & Exo & E & $\begin{array}{l}\text { PV, wind, } \\
\text { generator, battery }\end{array}$ & - & $\mathrm{x}$ & - & $\mathrm{x}$ & sub-hourly & commercial & [121] \\
\hline
\end{tabular}

$\mathrm{S}$ = Steady-state; T = Transient; Endo = Endogenous; Exo = Exogenous; T = Thermal demand; E = Electrical demand; PV = Photovoltaics; CHP = Combined Heat \& Power; HP = Heat Pump. 


\section{Tools for Transportation Energy Demand Modelling}

There are numerous transport modelling software products available on the market. The approach followed by these simulation engines may be either macroscopic (statistical dispersion models, freeway traffic models, etc.) or microscopic (multi-agent simulation, particle system simulation, etc.) [122]. Therefore, in general terms, there are two classes of models for transportation energy demand calculation: vehicle-based models that predict energy consumption based on the result of a microsimulation model, and macrosimulation models that use aggregate energy consumption data to predict transportation energy consumption with low spatial and temporal resolutions. The choice between both approaches will be based on the required level of detail since each approach has its own advantages and disadvantages. As stated in the review on traffic simulation software in reference [122], macrosimulation models do not examine the impacts a single vehicle may have in the traffic network, while microsimulation models are very detailed but may present issues with the use of computer memory. Similarly, from the energy consumption point of view, macroscopic models (based on average speed philosophy) relate the fuel consumption by transport to the average speed of links, while microsimulation models provide more accurate estimates of fuel consumption for a limited network application context. There is a wide spectrum of reviews on traffic simulation tools in the literature (e.g., [122,123]). Some examples of the mostly used micro- and macrosimulation tools introduced in these reviews are CUBE Dynasim [124], Paramics [125], EMME [126], SimTraffic [127], AIMSUN [128], VISSIM [129], and MatSIM [130]. Details on the characteristics of these tools are presented in Table 2. It must be noted that, in most of the cases, the environmental impact and thus energy consumption in the form of fossil fuel consumption is not directly assessed by the transport simulation tool but this calculation is exogenously done instead as a post-process with the use of fuel consumption factors/ratios).

An example of an USEM co-simulation platform which integrates transportation modelling by using an existing transport modelling tool is the urban platform CitySim [13]. This platform exogenously (specified by the user as a model input) integrates a stochastic transport model by using the MatSIM tool [130]. MATSim is a mesoscopic tool or low-fidelity microsimulation tool, as it has the intention of modelling very large scenarios and does not simulate so detailed models as microsimulation models do. Another example is LakeSIM urban platform [131], which includes the modelling suite for transportation system POLARIS [132] in order to facilitate the assessment of proposed transportation infrastructure. Also, non-motorized trips have been integrated in USEM. The USEM platform umi performs walkability evaluations of complete neighborhoods based on the sustainable transportation module developed by [133]. Walkability is calculated for each building based on a grid of streets and pedestrian pathways as well as amenities using custom Python scripts [6].

A thorough review on computer tools for modelling electric vehicle energy requirements and their impact on power distribution networks is presented in reference [123]. In their work, the authors include a vast list of simulation engines capable of simulating vehicle systems and control, renewable energy and vehicle-to-grid integration, impact analysis, traffic system simulation, etc. As concluded in reference [123], in most situations none of the reviewed tools will be adequate for analyzing and optimizing all aspects of the electric vehicle and the grid interaction. Accordingly, the capabilities of each of the tools are specified in reference [123] in order to find possible synergies among them. A selection of tools is presented on Table 3, together with the classification of some of their main modelling characteristics. 
Table 3. Characteristics of reviewed simulation tools for transport energy demand modelling.

\begin{tabular}{|c|c|c|c|c|c|c|c|}
\hline & Transient/Static & $\begin{array}{c}\text { Supports GIS } \\
\text { Integration }\end{array}$ & $\begin{array}{c}\text { Transport Energy Demand } \\
\text { Modelling }\end{array}$ & $\begin{array}{c}\text { Traffic Signal Timing } \\
\text { Optimization }\end{array}$ & Time Scale & Availability & References \\
\hline CUBE Dynasim & $\mathrm{T}$ & $\mathrm{x}$ & Micro-simulation & $\mathrm{x}$ & sub-hourly & commercial & [124] \\
\hline Paramics & $\mathrm{T}$ & - & Micro-simulation & $x$ & sub-hourly & commercial & [125] \\
\hline EMME/2 & $S$ & $\mathrm{x}$ & Micro-simulation & $\mathrm{x}$ & - & commercial & [126] \\
\hline SimTraffic & $\mathrm{T}$ & - & Micro-simulation & $\mathrm{x}$ & sub-hourly & commercial & [127] \\
\hline AIMSUN & $\mathrm{T}$ & $\mathrm{x}$ & Micro- and Macro-simulation & $\mathrm{x}$ & sub-hourly & commercial & [128] \\
\hline VISSIM & $\mathrm{T}$ & $\mathrm{x}$ & Micro-simulation & $\mathrm{x}$ & sub-hourly & commercial & [129] \\
\hline MATSim & $\mathrm{T}$ & $\mathrm{x}$ & Micro-simulation & $\mathrm{x}$ & sub-hourly & free, open-source & [130] \\
\hline POLARIS & $\mathrm{T}$ & $\mathrm{x}$ & Micro-simulation & $\mathrm{x}$ & sub-hourly & free, open-source & [132] \\
\hline
\end{tabular}




\section{Tools for Energy Optimization Modelling}

As USEM platforms have a great number of variables and input parameters, the number of possible combinations is very large. The probability of identifying a multi-objective optimal configuration of these variables by manual trial and error or simple parametric studies is correspondingly small. In order to overcome this problem, simulation-based optimization may be used. Within system optimization studies, the best performing set of parameters and technologies is identified by considering the accomplishment of a set of desired multi-objective criteria. Here, different optimization objectives (Objective functions) may be chosen, e.g., the minimization of primary energy demand, or the minimization of the cost of providing the entire energy supply system (like e.g., implemented in the SynCity urban model [134]). Also, different constraints (environmental emissions, resources) can be fixed in the objective function.

Optimizers coupled with simulation tools allow performing a scientific exploration of alternatives. Global Optimization algorithms have been in use for building thermal performance simulation for long. For example, the Generic Optimization Program GenOpt [135], freeware, can be customized for the minimization of a cost function that is evaluated by an external simulation program. It has been used for conducting optimization calculations with TRNSYS, Dymola, IDA ICE, ESP-r, EnergyPlus and DOE-2, among others $[136,137]$. Two comprehensive reviews on the most used optimization programs on building performance optimization and their key capabilities are presented in references $[138,139]$. The survey in reference [138] concludes that EnergyPlus and TRNSYS are the mostly used building simulation programs in building optimization studies, while the mostly used optimization engines or tools seem to be GenOpt and Matlab optimization toolboxes applied to building design optimization. Among the listed optimization tools, some more examples of commercial and free optimization solvers are: Altair HyperStudy, DAKOTA, GoSUM, iSIGHT, LionSolver, MOBO, MultiOpt, Opt-E-Plus, and TRNOPT (a GenOpt interface). Within the scope of building design optimization, fully-functional simulation-optimization tools have also been developed. An example of such platforms is the software BEopt [140], which is designed to find optimal building designs along the path to Zero Net Energy buildings. BEopt uses DOE-2 and EnergyPlus simulation engines to calculate the energy use of the building, and TRNSYS to calculate water-heating loads and energy savings for solar water heating and annual electrical energy production from a grid-connected PV system.

When extrapolating from single building design to the urban system scale, Global Optimization algorithms can also be applied to perform optimization studies. BEopt was used to assess the impact of DER technologies in an urban area by optimizing three defined building prototypes and extrapolating them to the city scale [141]. The CitySim platform uses a hybrid evolutionary algorithm to manipulate the geometric form of groups of buildings to optimize the potential utilization of solar energy by passive and active means [142] and therefore reduce the heating and cooling consumption of the buildings. The effectiveness of this new algorithm was validated in reference [143] by comparing its results against other global optimization algorithms such as the ones behind GenOpt. Another tool to apply Global Optimization algorithms to urban scale energy modelling is Galapagos [144]. This tool is used combined with Walkscore [145] (a tool for walkability metrics that yields the proximity of buildings to amenities) to enhance land-use allocation in a neighborhood with respect to minimizing transportation needs by car, and its output is used in the urban platform umi. Both previous examples relate to the use of global optimization techniques for the minimization of energy consumption (building energy demand and transport energy demand, respectively) in a district or city. Notwithstanding, optimization tools can also be applied to energy supply systems.

In terms of tools for the optimization of energy generation systems, a very detailed review on this topic is presented in reference [146]. Additionally, some of the tools introduced in Section 5.1 are able to perform both the simulation and the optimization of energy generation systems, i.e., HOMER, DER-CAM, RETScreen, or EnergyPLAN. Normally, these tools model energy supply and storage systems at a wide scale and find the optimal DER investments by minimizing the total energy costs, carbon dioxide emissions, or a combination of both criteria. However, it must be noted that a focus on 
the generation systems may not be sufficient when optimizing energy supply systems, as other issues need to be simultaneously optimized, e.g., distribution networks layout and costs. The optimization model presented in reference [147] overcomes this limitation by considering both the optimization of the logistics of energy resources/products and the networks layout between consumers and suppliers (both the electrical and thermal distribution).

In general, there are several tools in the market which have been developed for the optimization of energy distribution systems (both for the electricity sector and district thermal systems). The goal of the optimization in this case can be, for instance, to produce the most economical fuel combination by considering a variety of costs, or find the physical equilibrium of the energy distribution network. Examples of simulation tools that include optimization algorithms among the tools presented in Section 5.2 are NEPLAN, TERMIS, DIgSILENT PowerFactory). Also, many of the tools for transport energy demand simulation presented in Section 6 (e.g., Paramics, EMME, SimTraffic, and AIMSUN) include the optimization of traffic signal timings to minimize the total travel time of users and/or reduce the fuel consumption.

Regarding the overall energy-economics in USEM, Multi-Objective Energy System Optimization tools have been under development for long time. For example, the MARKAL/TIMES family [148] are energy/economic/environmental model generators to represent the evolution over a period of usually 20-50 years of a specific energy-environment system at the global, multi-regional, national, state/province, or community level. The main goal of this type of energy models is the identification of the least-cost energy systems and investment strategies or the identification of cost-effective responses to restrictions on environmental emissions and resource constraints. Even if MARKAL tools do not deal with 'fine grade' demand assessment, the energy-economy concepts they integrate may be useful for future USEM development.

\section{Conclusions}

The assessment and prediction of urban energy systems using Urban-Scale Energy Modelling platforms is becoming increasingly important. The main driver for this work was the fact that, even though there are a significant number of review articles on the topic, they do not normally differentiate specific existing simulation engines (able to tackle one or few analysis areas in the urban energy system) from published USEM platforms (expressly developed to cover several analysis areas in the urban energy system). In addition, not many review papers classify the available simulation engines according to their capabilities and the analysis area(s) of the urban energy system they cover.

In this paper, a general introduction and classification of relevant simulation engines aimed at building each of the sub-models in Urban-Scale Energy Modelling platforms has been provided, backed by the pertinent literature review of major publications on the topic. The selection of both free and commercial simulation tools for USEM has been classified in Tables 1-3, indicating the main capabilities of each tool concerning the analysis of the environment, energy demand, energy generation, energy distribution, and optimization. The preceding sections have shown that there is a very wide range of simulation engines available for the modelling of each of the analysis areas or sub-models that a complete USEM platform may include.

Firstly, both commercial and freely-available simulation engines for urban climate modelling can easily be found. However, the integration of these tools with building performance simulation software is mainly done in a sequential manner (where the microclimate is a predetermined boundary condition), whereas it should be considered that the strong interaction between the local microclimate and the buildings' energy demand may be better represented by co-simulation approaches.

The analysis of building stock energy demand at the urban level needs both the characterization of building stock itself and the simulation of the energy demand of such buildings. For building geometry characterization, the integration of tools for digital image processing and GIS has been widely applied. Nevertheless, due to the limitations of most of the GIS tools in terms of poorly attributed building semantical information, City Information Modelling (CIM) tools are being developed. An example of 
a well-developed and established semantic model in digital city is CityGML, a tool for the modelling and exchange of 3D city and landscape models, which is quickly being adopted (mainly in Europe) as an international standard for representing and storing 3D city models. Well-known commercial or public-domain building performance simulation software have been broadly used to compute the results of the building energy demand sub-model in USEM. Accordingly, there are a significant number of available simulation engines as well as representative review papers on this topic. In fact, it is common to find urban platforms that use such tools and put an emphasis on the bottom-up building demand generation of the urban energy system.

Notwithstanding this, a complete simulation of a district energy system requires the calculation of the energy flows of networks and grids by considering the energy supply from both central systems and distributed systems. Indeed, there are a variety of available simulation engines for energy infrastructure modelling (mainly for district heating networks and electrical grids), thus energy distribution modelling within more complex USEM platforms should take advantage of the available tools. In the specific case of power grid simulation, there is a meaningful variety of free and commercial software packages available (due to the engineering requirements of the industry), which could be coupled to other sub-models within USEM.

Transportation modelling has been widely developed in the last decades. This implies that well-established transportation modelling tools are available, although their focus is not the modelling of transportation energy consumption. In general terms, macroscopic transportation modelling tools calculate the transport fuel consumption based on the average speed of links, while microsimulation modelling tools provide more accurate estimates of fuel consumption for a limited network application context. In any of the cases, this calculation is commonly done in an exogenous manner (as a post-process with the use of fuel consumption factors/ratios). To date, transportation modelling tools have been scarcely integrated in wider urban-scale energy models. The vast majority of these tools focus on modelling the individual traffic behavior and include optimization based on specific criteria, as for example the optimization of signal timings to reduce fuel consumption.

Finally, simulation-based optimization tools have also been in use for building thermal performance simulation for a long time. When extrapolating from single building design to urban system scale, Global Optimization algorithms can also be applied. There are existing tools that allow the use of global optimization techniques for the minimization of energy consumption (building energy demand and transport energy demand) in a district or city, as well as the optimization of energy supply systems. It is also common to find optimization tools in the market aimed at producing the most economical fuel combination by considering a variety of costs, or finding the physical equilibrium of the distribution networks. In a different time and physical boundary scales, Multi-Objective Energy System Optimization tools have been under development for long time in the form of energy/economic/environmental model generators. They represent the evolution over a period of usually 20-50 years of a specific energy-environment system at the global, multi-regional, national, state/province, or community level. The main goal of this type of energy models is the identification of the least-cost energy systems and investment strategies, or the identification of cost-effective responses to restrictions on environmental emissions and resource constraints.

With the present work, the ambition is that the given information can help users in academia and in industry with the selection of suitable simulation tools to address Urban-Scale Energy Modelling problems. In contrast to some of the existing USEM reviews which are focused on tools for the simulation of building stock energy demand, the present paper additionally reviews tools for urban meteorology analysis, building energy supply modelling, transportation energy demand modelling, and energy optimization.

Author Contributions: Conceptualization, A.S., C.C., J.S., M.S.; Methodology, A.S., C.C., J.S., M.S.; Software, A.S., C.C., J.S., M.S. All authors have equal contribution.

Funding: This research was funded by the research and innovation program Horizon 2020 of the European Union under the grant agreement nr. 646456 (GrowSmarter) as well as the GEIDI project (ref. TIN2016-78473-C3-3-R) 
financed by the Ministry of Economy and Competitiveness of Spain. C. Corchero work is supported by the grant IJCI-2015-26650 (MICINN).

Conflicts of Interest: The authors declare no conflict of interest.

\section{References}

1. Masanet, E.R.; Poponi, D.; Bryant, T.; Burnard, K.; Cazzola, P.; Dulac, J.; Pales, A.F.; Husar, J.; Janoska, P.; Munuera, L. Energy Technology Perspectives 2016-Towards Sustainable Urban Energy Systems; International Energy Agency: Paris, France, 2016; ISBN 92-64-25234-7.

2. Allegrini, J.; Orehounig, K.; Mavromatidis, G.; Ruesch, F.; Dorer, V.; Evins, R. A review of modelling approaches and tools for the simulation of district-scale energy systems. Renew. Sustain. Energy Rev. 2015, 52, 1391-1404. [CrossRef]

3. Manfren, M.; Caputo, P.; Costa, G. Paradigm shift in urban energy systems through distributed generation: Methods and models. Appl. Energy 2011, 88, 1032-1048. [CrossRef]

4. Crawley, D.B.; Lawrie, L.K.; Winkelmann, F.C.; Buhl, W.F.; Huang, Y.J.; Pedersen, C.O.; Strand, R.K.; Liesen, R.J.; Fisher, D.E.; Witte, M.J. EnergyPlus: Creating a new-generation building energy simulation program. Energy Build. 2001, 33, 319-331. [CrossRef]

5. Bollinger, L.A.; Evins, R. HUES: A holistic urban energy simulation platform for effective model integration. In Proceedings of the International Conference CISBAT 2015 Future Buildings and Districts Sustainability from Nano to Urban Scale, Lausanne, Switzerland, 9-11 September 2015; LESO-PB: Lausanne, Switzerland; EPFL: Lausanne, Switzerland, 2015; pp. 841-846.

6. Reinhart, C.F.; Dogan, T.; Jakubiec, J.A.; Rakha, T.; Sang, A. Umi-an urban simulation environment for building energy use, daylighting and walkability. In Proceedings of the 13th Conference of International Building Performance Simulation Association, Chambery, France, 26-28 August 2013.

7. Harish, V.S.K.V.; Kumar, A. A review on modeling and simulation of building energy systems. Renew. Sustain. Energy Rev. 2016, 56, 1272-1292. [CrossRef]

8. Li, W.; Zhou, Y.; Cetin, K.; Eom, J.; Wang, Y.; Chen, G.; Zhang, X. Modeling urban building energy use: A review of modeling approaches and procedures. Energy 2017, 141, 2445-2457. [CrossRef]

9. Remund, J.; Kunz, S. METEONORM: Global Meteorological Database for Solar Energy and Applied Climatology; Meteotest: Bern, Switzerland, 1997.

10. Jentsch, M.F.; James, P.A.; Bourikas, L.; Bahaj, A.S. Transforming existing weather data for worldwide locations to enable energy and building performance simulation under future climates. Renew. Energy 2013, 55, 514-524. [CrossRef]

11. Dickinson, R. Generating future weather files for resilience. In Proceedings of the International Conference on Passive and Low Energy Architecture, PLEA 2016-Cities, Buildings, People: Towards Regenerative Environments, Los Angeles, CA, USA, 11-13 July 2016.

12. Baklanov, A.; Grimmond, C.S.B.; Carlson, D.; Terblanche, D.; Tang, X.; Bouchet, V.; Lee, B.; Langendijk, G.; Kolli, R.K.; Hovsepyan, A. From urban meteorology, climate and environment research to integrated city services. Urban Clim. 2018, 23, 330-341. [CrossRef]

13. Robinson, D.; Haldi, F.; Kämpf, J.; Leroux, P.; Perez, D.; Rasheed, A.; Wilke, U. CitySim: Comprehensive micro-simulation of resource flows for sustainable urban planning. In Proceedings of the Building Simulation, Glasgow, Scotland, 27-30 July 2009; pp. 1614-1627.

14. Ooka, R. Recent development of assessment tools for urban climate and heat-island investigation especially based on experiences in Japan. Int. J. Climatol. J. R. Meteorol. Soc. 2007, 27, 1919-1930. [CrossRef]

15. Robinson, D. 15 Integrated resource flow modelling of the urban built environment. Build. Perform. Simul. Des. Oper. 2011, 441.

16. Yang, X.; Zhao, L.; Bruse, M.; Meng, Q. An integrated simulation method for building energy performance assessment in urban environments. Energy Build. 2012, 54, 243-251. [CrossRef]

17. Bruse, M. Modelling and strategies for improved urban climates. In Proceedings International Conference on Urban Climatology E International Congress of Biometeorology; Citeseer: Gaithersburg, MD, USA, 1999; pp. 8-12.

18. Huttner, S.; Bruse, M. Numerical modeling of the urban climate-a preview on ENVI-met 4.0. In Proceedings of the 7th International Conference on Urban Climate ICUC-7, Yokohama, Japan, 29 June-3 July 2009; Volume 29. 
19. Matzarakis, A.; Rutz, F.; Mayer, H. Modelling radiation fluxes in simple and complex environments: Basics of the RayMan model. Int. J. Biometeorol. 2010, 54, 131-139. [CrossRef] [PubMed]

20. Matzarakis, A.; Fröhlich, D.; Gangwisch, M.; Ketterer, C.; Peer, A. Developments and applications of thermal indices in urban structures by RayMan and SkyHelios model. In Proceedings of the ICUC9 9th International Conference on the Urban Climate Jointly with the 12th Symposium on the Urban Environment, Freiburg, Germany, 23 April 2015.

21. Sievers, V. The Model MUKLIMO_3, Special Aspects and Extensions; Deutscher Wetterdienst: Offenback, Germany, 2001.

22. Simon, H. Modeling Urban Microclimate: Development, Implementation and Evaluation of New and Improved Calculation Methods for the Urban Microclimate Model ENVI-Met; 2016.

23. Larson, G.W.; Shakespeare, R. Rendering with Radiance: The Art and Science of Lighting Visualization; Booksurge Llc: Charleston, SC, USA, 2004; ISBN 0-9745381-0-8.

24. Polly, B.; Kutscher, C.; Macumber, D.; Schott, M.; Pless, S.; Livingood, B.; Van Geet, O. From Zero Energy Buildings to Zero Energy Districts; NREL (National Renewable Energy Laboratory): Golden, CO, USA, 2016.

25. Bueno, B.; Norford, L.; Hidalgo, J.; Pigeon, G. The urban weather generator. J. Build. Perform. Simul. 2013, 6, 269-281. [CrossRef]

26. Bueno, B.; Roth, M.; Norford, L.; Li, R. Computationally efficient prediction of canopy level urban air temperature at the neighbourhood scale. Urban Clim. 2014, 9, 35-53. [CrossRef]

27. Nakano, A. Urban Weather Generator User Interface Development: Towards a Usable Tool for Integrating Urban Heat Island Effect within Urban Design Process; Massachusetts Institute of Technology: Cambridge, MA, USA, 2015.

28. McNeel, R.; Rhinoceros. NURBS Modleing for Windows. 2015. Available online: http:/ /www.rhino3d.com/ jewelry.htm (accessed on 30 October 2018).

29. Rasheed, A. Multiscale Modelling of Urban Climate; EPFL: Lausanne, Switzerland, 2009.

30. Ledoux, H.; Meijers, M. Extruding building footprints to create topologically consistent 3D city models. In Urban and Regional Data Management; CRC Press: Boca Raton, FL, USA, 2009; pp. 51-60.

31. Ledoux, H.; Meijers, M. Topologically consistent 3D city models obtained by extrusion. Int. J. Geogr. Inf. Sci. 2011, 25, 557-574. [CrossRef]

32. Ghawana, T.; Zlatanova, S. Data Consistency Checks for Building of 3D Model: A Case Study of Technical University, Delft Campus, The Netherlands; Geospatial World: Rotterdam, The Netherlands, 2010.

33. Ratti, C. LT Urban-The energy modeling of urban form. Proc. PLEA2000 2000, 660-665.

34. Ratti, C.; Baker, N.; Steemers, K. Energy consumption and urban texture. Energy Build. 2005, 37, 762-776. [CrossRef]

35. Richens, P. Image processing for urban scale environmental modelling. In Proceedings 5th Intemational IBPSA Conference: Building Simulation 97; University of Bath: Bath, UK, 1997; pp. 163-171.

36. Ratti, C.; Di Sabatino, S.; Britter, R. Urban texture analysis with image processing techniques: Winds and dispersion. Theor. Appl. Climatol. 2006, 84, 77-90. [CrossRef]

37. Gonzalez, R.C.; Woods, R.E.; Eddins, S.L. Digital Image Processing Using MATLAB; Pearson-Prentice-Hall Upper Saddle River: Saddle River, NJ, USA, 2004; Volume 624.

38. Neidhart, H.; Sester, M. Identifying building types and building clusters using 3-D laser scanning and GIS-data. Int. Arch. Photogramm. Remote Sens. Spatial Inf. Sci. 2004, 35, 715-720.

39. Geiß, C.; Taubenböck, H.; Wurm, M.; Esch, T.; Nast, M.; Schillings, C.; Blaschke, T. Remote sensing-based characterization of settlement structures for assessing local potential of district heat. Remote Sens. 2011, 3, 1447-1471. [CrossRef]

40. Massimo, D.E.; Barbalace, A.; Marzo-Micale, A. GIS, 3D city modeling and green urban conservation. In Proceedings of the 30th Esri International User Conference, San Diego, CA, USA, 12-16 July 2010.

41. Reiter, S.; Wallemacq, V. City energy management: A case study on the area of Liège in Belgium. In Proceedings of the International Conference GEOProcessing, Valencia, Spain, 29 January-4 February 2011; IARIA: Barcelona, Spain, 2011; pp. 1-6.

42. Kulkarni, S.; Banerjee, R. Renewable energy mapping in Maharashtra; India using GIS. In Proceedings of the World Renewable Energy Congress-Sweden, Linköping, Sweden, 8-13 May 2011; Linköping University Electronic Press: Linköping, Sweden, 2011; pp. 3177-3184. 
43. Huber, J.; Nytsch-Geusen, C. Development of modeling and simulation strategies for large-scale urban districts. In Proceedings of the Building Simulation, Sydney, Australia, 14-16 November 2011; Volume 2011, pp. 1753-1760.

44. Sketchup Software. Available online: https://www.sketchup.com/ (accessed on 30 October 2018).

45. Saygi, G.; Agugiaro, G.; Hamamcioğlu-Turan, M.; Remondino, F. Evaluation of GIS and BIM roles for the information management of historical buildings. ISPRS Ann. Photogramm. Remote Sens. Spat. Inf. Sci. 2013, 2, 283-288. [CrossRef]

46. Hu, X.; Liu, X.; He, Z.; Zhang, J. Batch Modeling of 3D City Based on ESRI Cityengine; IET: Stevenage, UK, 2013.

47. Xu, X.; Ding, L.; Luo, H.; Ma, L. From building information modeling to city information modeling. J. Inf. Technol. Constr. (ITcon) 2014, 19, 292-307.

48. Kolbe, T.H.; Gröger, G.; Plümer, L. CityGML: Interoperable access to 3D city models. In Geo-Information for Disaster Management; Springer: New York, NY, USA, 2005; pp. 883-899.

49. Gröger, G.; Kolbe, T.H.; Nagel, C.; Hafele, K.H. OpenGIS City Geography Markup Language (CityGML) Encoding Standard (OGC 12-019); Version 2.0. 0. OGC 12-019; Open Geospatial Consortium: Wayland, MA, USA, 2014.

50. Nouvel, R.; Zirak, M.; Dastageeri, H.; Coors, V.; Eicker, U. Urban energy analysis based on 3D city model for national scale applications. In Proceedings of the IBPSA Germany Conference, Aachen, Germany, 22-24 September 2014; Volume 8.

51. Monien, D.; Strzalka, A.; Koukofikis, A.; Coors, V.; Eicker, U. Comparison of building modelling assumptions and methods for urban scale heat demand forecasting. Future Cities Environ. 2017, 3, 2. [CrossRef]

52. Remmen, P.; Lauster, M.; Mans, M.; Osterhage, T.; Müller, D. CityGML Import and Export for Dynamic Building Performance Simulation in Modelica. In Proceedings of the Building Simulation and Optimization Conference (BSO16), Newcastle University, Newcastle upon Tyne, UK, 12-14 September 2016; pp. 329-336.

53. Hong, T.; Chen, Y.; Lee, S.H.; Piette, M.A. CityBES: A web-based platform to support city-scale building energy efficiency. Urban Comput. 2016. [CrossRef]

54. Autodesk AutoCAD Software. Available online: https://www.autodesk.es/ (accessed on 30 October 2018).

55. Google Earth. Available online: https://www.google.com/earth/ (accessed on 30 October 2018).

56. Swan, L.G.; Ugursal, V.I. Modeling of end-use energy consumption in the residential sector: A review of modeling techniques. Renew. Sustain. Energy Rev. 2009, 13, 1819-1835. [CrossRef]

57. Crawley, D.B.; Hand, J.W.; Kummert, M.; Griffith, B.T. Contrasting the capabilities of building energy performance simulation programs. Build. Environ. 2008, 43, 661-673. [CrossRef]

58. Reinhart, C.F.; Davila, C.C. Urban building energy modeling-A review of a nascent field. Build. Environ. 2016, 97, 196-202. [CrossRef]

59. Birdsall, B.; Buhl, W.F.; Ellington, K.L.; Erdem, A.E.; Winkelmann, F.C. Overview of the DOE-2 Building Energy Analysis Program, Version 2.1 D; U.S. Department of Energy: Washington, DC, USA, 1990.

60. Huang, Y.J.; Brodrick, J. A Bottom-up Engineering Estimate of the Aggregate Heating and Cooling Loads of the Entire US Building Stock; Lawrence Berkeley National Laboratory: Guangdong, China, 2000.

61. Hirsch, J.J. eQuest, the QUick Energy Simulation Tool. 2006. Available online: http:/ /www.doe2.com/equest (accessed on 30 October 2018).

62. Heiple, S.; Sailor, D.J. Using building energy simulation and geospatial modeling techniques to determine high resolution building sector energy consumption profiles. Energy Build. 2008, 40, 1426-1436. [CrossRef]

63. ESRU, O. The ESP-r System for Building Energy Simulation: User Guide Version 10 Series; University of Strathclyde: Glasgow, Scotland, 2003.

64. Swan, L.; Ugursal, V.I.; Beausoleil-Morrison, I. Implementation of a Canadian residential energy end-use model for assessing new technology impacts. In Proceedings of Building Simulation, Glasgow; Citeseer: Gaithersburg, MD, USA, 2009; pp. 1429-1436.

65. Matsuo, Y. HASP/ACLD/ACSS 8501. In Tokyo: Japan Building Mechanics Engineers Association; 1985.

66. Shimoda, Y.; Fujii, T.; Morikawa, T.; Mizuno, M. Development of residential energy end-use simulation model at city scale. In Proceedings of the Eighth International IBPSA Conference, Eindhoven, The Netherlands, 11-14 August 2003.

67. Yuan, J.; Farnham, C.; Emura, K.; Alam, M.A. Proposal for optimum combination of reflectivity and insulation thickness of building exterior walls for annual thermal load in Japan. Build. Environ. 2016, 103, $228-237$. [CrossRef]

68. NRCan HOT2000 V. 7.10 User's Manual for DOS and MacIntosh Computers; 1995. 
69. Guler, B.; Ugursal, V.I.; Fung, A.S.; Aydinalp-Koksal, M. Impact of energy efficiency upgrade retrofits on the residential energy consumption and Greenhouse Gas emissions in Canada. Int. J. Environ. Technol. Manag. 2008, 9, 434-444. [CrossRef]

70. Klein, S.A. TRNSYS-A transient system simulation program. In University of Wisconsin-Madison, Engineering Experiment Station Report; National Library of Australia: Canberra, Australia, 1988; pp. 12-38.

71. Salom, J. Study of the Residential Building Sector in the Plan for Energy Improvement of Barcelona. In Proceedings EuroSun2002-Congress; ISES-Europe: Bologna, Italy, 2002.

72. Perini, K.; Palme, M.; Salvati, A. UWG -TRNSYS Simulation Coupling for Urban Building Energy Modelling. 7. Available online: https:/ / bura.brunel.ac.uk/bitstream/2438/16798/1/Fultext.pdf (accessed on 30 October 2018).

73. Fritzson, P.; Engelson, V. Modelica-A unified object-oriented language for system modeling and simulation. In European Conference on Object-Oriented Programming; Springer: New York, NY, USA, 1998; pp. 67-90.

74. Wetter, M.; Zuo, W.; Nouidui, T.S.; Pang, X. Modelica buildings library. J. Build. Perform. Simul. 2014, 7, 253-270. [CrossRef]

75. Lauster, M.; Teichmann, J.; Fuchs, M.; Streblow, R.; Mueller, D. Low order thermal network models for dynamic simulations of buildings on city district scale. Build. Environ. 2014, 73, 223-231. [CrossRef]

76. Baetens, R.; De Coninck, R.; Van Roy, J.; Verbruggen, B.; Driesen, J.; Helsen, L.; Saelens, D. Assessing electrical bottlenecks at feeder level for residential net zero-energy buildings by integrated system simulation. Appl. Energy 2012, 96, 74-83. [CrossRef]

77. Lacoste, B.; Wolf, A.; Witzig, A.; Märklin, A. Polysun: PV, Wind and Power-Heat-Cogeneration in one Design Tool. In Proceedings of the 5th European PV-Hybrid and Mini-Grid Conference by OTTI, Tarragona, Spain, 29-30 April 2010; pp. 29-30.

78. Bornatico, R.; Pfeiffer, M.; Witzig, A.; Guzzella, L. Optimal sizing of a solar thermal building installation using particle swarm optimization. Energy 2012, 41, 31-37. [CrossRef]

79. Kalamees, T. IDA ICE: The simulation tool for making the whole building energy and HAM analysis. Annex 2004, 41, 12-14.

80. Krüger, E.; Pearlmutter, D.; Rasia, F. Evaluating the impact of canyon geometry and orientation on cooling loads in a high-mass building in a hot dry environment. Appl. Energy 2010, 87, 2068-2078. [CrossRef]

81. Courchesne-Tardif, A.; Kummert, M.; Demark, S.; Butler, T.; Pearl, D.; Jones, S.; Charneux, R.; Genest, F.; Picard, D. Assessing community-scale energy supply scenarios using TRNSYS simulations. In Proceedings of Building Simulation; Citeseer: Gaithersburg, MD, USA, 2011.

82. Elsheikh, A.; Widl, E.; Pensky, P.; Dubisch, F.; Brychta, M.; Basciotti, D.; Müller, W. Modelica-enabled rapid prototyping via TRNSYS. In Proceedings of the 13th International Conference of the International Building Performance Simulation Association, Chambéry, France, 25-28 August 2013.

83. Nouidui, T.; Wetter, M.; Zuo, W. Functional mock-up unit for co-simulation import in EnergyPlus. J. Build. Perform. Simul. 2014, 7, 192-202. [CrossRef]

84. DOE OpenStudio Website. Available online: https://www.openstudio.net/ (accessed on 30 October 2018).

85. Guglielmetti, R.; Macumber, D.; Long, N. OpenStudio: An open source integrated analysis platform. In Proceedings of the 12th Conference of International Building Performance Simulation Association, Sydney, Australia, 14-16 November 2011.

86. R Core Team. A Language and Environment for Statistical Computing; R Foundation for Statistical Computing: Vienna, Austria, 2015.

87. Wiech, M.; Szczesny, W. Gradestat-Noncommercial statistical application using grade algorithms and methods to make synthesis of information. In Information Systems in Management III; 2009; p. 121.

88. Van Rossum, G.; Drake, F.L. The Python Language Reference Manual; Network Theory Ltd.: Eastbourne, UK, 2011; ISBN 1-906966-14-1.

89. Arnold, K.; Gosling, J.; Holmes, D. The Java Programming Language; Addison Wesley Professional: Boston, MA, USA, 2005; ISBN 0-321-34980-6.

90. Gajowniczek, K.; Nafkha, R.; Zabbkowski, T. Electricity peak demand classification with artificial neural networks. In Proceedings of the 2017 Federated Conference on Computer Science and Information Systems (FedCSIS), Prague, Czech Republic, 3-6 September 2017; pp. 307-315. 
91. Zabkowski, T.; Gajowniczek, K.; Szupiluk, R. Grade analysis for energy usage patterns segmentation based on smart meter data. In Proceedings of the 2015 IEEE 2nd International Conference on Cybernetics (CYBCONF), Gdynia, Poland, 24-26 June 2015; p. 234.

92. Monari, F.; Strachan, P. CALIBRO: An R package for the automatic calibration of building energy simulation models. In Proceedings of the Building Simulation 2017, San Francisco, CA, USA, 7-9 August 2017.

93. Best, R.E.; Flager, F.; Lepech, M.D. Modeling and optimization of building mix and energy supply technology for urban districts. Appl. Energy 2015, 159, 161-177. [CrossRef]

94. Keirstead, J.; Jennings, M.; Sivakumar, A. A review of urban energy system models: Approaches, challenges and opportunities. Renew. Sustain. Energy Rev. 2012, 16, 3847-3866. [CrossRef]

95. Connolly, D.; Lund, H.; Mathiesen, B.V.; Leahy, M. A review of computer tools for analysing the integration of renewable energy into various energy systems. Appl. Energy 2010, 87, 1059-1082. [CrossRef]

96. Gao, Y.; Meng, X.; Gao, W.; Long, E. A review of technologies and evaluation softwares for distributed energy source system. Procedia-Soc. Behav. Sci. 2016, 216, 398-408. [CrossRef]

97. Energypro. Available online: https:/ /www.emd.dk/energypro/ (accessed on 30 October 2018).

98. Homer, N. HOMER Computer Software, Version 2.68 Beta; HOMER Energy LLC: Boulder, CO, USA, 2011.

99. Firestone, R. Distributed Energy Resources Customer Adoption Model Technology Data; Berkeley Lab: Berkeley, CA, USA, 2004.

100. Leng, G.J. RETScreen ${ }^{\mathrm{TM}}$ international: A decHOMER Energy LLCision support and capacity building tool for assessing potential renewable energy projects. Ind. Environ. Paris 2000, 23, 22-23.

101. Lund, H. Energyplan-advanced energy systems analysis computer model. Doc. Version 2011, 9.

102. Olsthoorn, D.; Haghighat, F.; Mirzaei, P.A. Integration of storage and renewable energy into district heating systems: A review of modelling and optimization. Sol. Energy 2016, 136, 49-64. [CrossRef]

103. Gabrielaitienè, I. Numerical simulation of a district heating system with emphases on transient temperature behaviour. In Proceedings of the the 8th International Conference of Environmental Engineering, Ilnius, Lithuania, 19-20 May 2011.

104. Dalla Rosa, A.; Christensen, J.E. Low-energy district heating in energy-efficient building areas. Energy 2011, 36, 6890-6899. [CrossRef]

105. Termis District Energy Optimization Software. Available online: http://software.schneider-electric.com/ products/termis / (accessed on 30 October 2018).

106. NetSim Software. Available online: https://www.vitecsoftware.com/en/product-areas/energy/products/ netsim-grid-simulation/ (accessed on 30 October 2018).

107. Silvennoinen, E.; Juslin, K.; Hänninen, M.; Tiihonen, O.; Kurki, J.; Porkholm, K. The APROS software for process simulation and model development. In Technical Research Centre of Finland. Research Report; 1989.

108. Fan, J.; Furbo, S.; Svendsen, S. TRNSYS Simulation of the Consumer Unit for Low Energy District Heating Net; Technical University of Denmark (DTU): Lyngby, Denmark, 2008.

109. Heymann, M.; Rühling, K.; Felsmann, C. Integration of Solar Thermal Systems into District Heating-DH system simulation. Energy Procedia 2017, 116, 394-402. [CrossRef]

110. Schafer, K.; Schlegel, F.; Pauschinger, T. Decentralized feed-in of solar heat into district heating networks-a technical analysis of realized plants. In Proceedings of the Book of Papers of the 2nd International Solar District Heating Conference, Hamburg, Germany, 3-4 June 2014; pp. 3-4.

111. López Villada, J. Integración de Sistemas de Refrigeración Solar en Redes de Distrito de Frío y de Calor; Universitat Rovira i Virgili: Tarragona, Spain, 2010; ISBN 84-693-9443-6.

112. Lozano, M.A.; Anastasia, A.; Palacín, F.; Serra, L.M. Simulation Study and Economic Analysis of Large-Scale Solar Heating Plants in Spain; EUROSUN: Graz, Austria, 2010.

113. Deschaintre, L. Development of a solar district heating online calculation tool. Energy Procedia 2014, 48, 1065-1075. [CrossRef]

114. Neplan Software. Available online: https://www.neplan.ch/ (accessed on 30 October 2018).

115. Hay, S.; Ferguson, A. A Review of Power System Modelling Platforms and Capabilities; The Institute of Engineering and Technology: Stevenage, UK, 2015.

116. DIgSILENT Power Factory Website, DIgSILENT GmbH. Available online: https://www.digsilent.de/en/ powerfactory.html (accessed on 30 October 2018).

117. Henning, D. MODEST: Model for optimization of dynamic energy systems with time dependent components and boundary conditions. In Interdisciplinary Energy System Methodology; 2011; p. 44. 
118. Zimmerman, R.D.; Murillo-Sánchez, C.E.; Thomas, R.J. MATPOWER: Steady-state operations, planning, and analysis tools for power systems research and education. IEEE Trans. Power Syst. 2011, 26, 12-19. [CrossRef]

119. PyPower Sotware. Available online: https://pypi.org/project/PYPOWER/ (accessed on 30 October 2018).

120. ETAP Website. Available online: http://etap.com/electrical-power-systemsoftware/etap-products.htm (accessed on 30 October 2018).

121. IPSA Website. Available online: http://www.ipsa-power.com/ (accessed on 30 October 2018).

122. Kotusevski, G.; Hawick, K.A. A Review of Traffic Simulation Software; Massey University: Wellington, New Zealand, 2009.

123. Mahmud, K.; Town, G.E. A review of computer tools for modeling electric vehicle energy requirements and their impact on power distribution networks. Appl. Energy 2016, 172, 337-359. [CrossRef]

124. CITILABS CUBE-Transportation \& Land-Use Modeling Software. Available online: http:/ /www.citilabs. com/software/cube/ (accessed on 30 October 2018).

125. Quadstone Paramics Software. Available online: http://www.paramics-online.com/index.php (accessed on 30 October 2018).

126. EMME Software. Available online: https://www.inrosoftware.com/en/products/emme/ (accessed on 30 October 2018).

127. Trafficware Software. Available online: http://www.trafficware.com/blog/category/simtraffic (accessed on 30 October 2018).

128. Aimsun Software. Available online: http://www.aimsun.com/site/ (accessed on 30 October 2018).

129. PTV Group Website. Available online: http://vision-traffic.ptvgroup.com/en-us/products/ptv-vissim/ (accessed on 30 October 2018).

130. MATSim Website. Available online: https://matsim.org/ (accessed on 30 October 2018).

131. Bergerson, J.; Muehleisen, R.T.; Rodda, W.B.; Auld, J.A.; Guzowski, L.B.; Ozik, J.; Collier, N. Designing future cities: LakeSIM integrated design tool for assessing short and long term impacts of urban scale conceptual designs. ISOCARP Rev. 2015, 11.

132. Auld, J.; Hope, M.; Ley, H.; Sokolov, V.; Xu, B.; Zhang, K. POLARIS: Agent-based modeling framework development and implementation for integrated travel demand and network and operations simulations. Transp. Res. Part C Emerg. Technol. 2016, 64, 101-116. [CrossRef]

133. Rakha, T.; Reinhart, C.F. A carbon impact simulation-based framework for land use planning and non-motorized travel behavior interactions. In Proceedings of the Building Simulation, Chambéry, France, 25-28 August 2013; pp. 25-28.

134. Keirstead, J.; Samsatli, N.; Shah, N. SynCity: An integrated tool kit for urban energy systems modelling. In Energy Efficient Cities: Assessment Tools and Benchmarking Practices; 2010; pp. 21-42.

135. GenOpt Website. Available online: https://simulationresearch.lbl.gov/GO/ (accessed on 30 October 2018).

136. Wetter, M. GenOpt (R), Generic Optimization Program, User Manual, Version 2.0.0; 2003.

137. Wetter, M.; Wright, J. A comparison of deterministic and probabilistic optimization algorithms for nonsmooth simulation-based optimization. Build. Environ. 2004, 39, 989-999. [CrossRef]

138. Nguyen, A.-T.; Reiter, S.; Rigo, P. A review on simulation-based optimization methods applied to building performance analysis. Appl. Energy 2014, 113, 1043-1058. [CrossRef]

139. Evins, R. A review of computational optimisation methods applied to sustainable building design. Renew. Sustain. Energy Rev. 2013, 22, 230-245. [CrossRef]

140. Christensen, C.; Anderson, R.; Horowitz, S.; Courtney, A.; Spencer, J. BEoptTM Software for Building Energy Optimization: Features and Capabilities. In National Renewable Energy Laboratory (NREL) Technical Report; 2006.

141. Burdjalov, D.; Daukoru, S.M.; Duer, A. Assessing Aggregated Impacts of Distributed Energy Resources (DERs): A Building Stock Model Approach.

142. Kämpf, J.H.; Robinson, D. Optimisation of building form for solar energy utilisation using constrained evolutionary algorithms. Energy Build. 2010, 42, 807-814. [CrossRef]

143. Kämpf, J.H. On the modelling and optimisation of urban energy fluxes. 2009. [CrossRef]

144. Rutten, D. Evolutionary Principles Applied to Problem Solving Using Galapagos; AAG10: Vienna, Austria, 2010.

145. Walkscore Website. Available online: http:/ / www.walkscore.com (accessed on 30 October 2018). 
146. Bazmi, A.A.; Zahedi, G. Sustainable energy systems: Role of optimization modeling techniques in power generation and supply-A review. Renew. Sustain. Energy Rev. 2011, 15, 3480-3500. [CrossRef]

147. Fazlollahi, S.; Becker, G.; Maréchal, F. Multi-objectives, multi-period optimization of district energy systems: III. Distribution networks. Comput. Chem. Eng. 2014, 66, 82-97. [CrossRef]

148. MARKAL/TIMES Website. Available online: https://www.energyplan.eu/othertools/national/ markaltimes / (accessed on 30 October 2018). 